\title{
Hepatitis virus and hepatocellular carcinoma in Brazil: a report from the State of Espírito Santo
}

\author{
Patrícia Lofêgo Gonçalves ${ }^{[1]}$, Maria da Penha Zago-Gomes ${ }^{[1]}$, Carlos Sandoval Gonçalves ${ }^{[1]}$ \\ and Fausto Edmundo Lima Pereira ${ }^{[2]}$
}

[1]. Hospital Universitário Cassiano Antonio de Morais, Universidade Federal do Espírito Santo, Vitória, ES. [2]. Núcleo de Doenças Infecciosas, Centro de Ciências da Saúde, Universidade Federal do Espírito Santo, Vitória, ES.

\begin{abstract}
Introduction: Few studies have examined hepatocellular carcinoma (HCC) in Brazil, and the incidence and risk factors for this type of malignancy vary greatly geographically. In this paper, we report several risk factors associated with HCC diagnosed at the University Hospital in Vitória, ES, Brazil. Methods: We reviewed 274 cases of HCC (January 1993 to December 2011) in which hepatitis B (HBV) and C (HCV) virus infection and chronic alcoholism were investigated. A diagnosis of hepatocellular carcinoma was confirmed by histology or by the presence of a characteristic pattern on imaging. Results: HCC with associated liver cirrhosis was noted in $85.4 \%$ of cases. The mean ages of men and women were 56.6 years and 57.5 years, respectively. The male-to-female ratio was 5.8:1. Associated risk factors included the following: HBV, 37.6\% (alone, 23.4\%; associated with chronic alcoholism, 14.2\%); HCV, 22.6\% (alone, 13.5\%; associated with chronic alcoholism, 9.1\%), chronic alcoholism, 17.1\%, non-alcoholic steatohepatitis, $2.6 \%$ and cryptogenic, $19.3 \%$. The male-to-female ratio was higher in cases associated with HBV or chronic alcoholism compared with HCV-associated or cryptogenic cases. In 40 cases without associated cirrhosis, the maleto-female ratio and mean age were lower than those in cirrhosis-associated cases. Conclusions: These results demonstrate that the main risk factor associated with HCC in the State of Espírito Santo is HBV. Chronic alcoholism is an important etiological factor, alone or in association with HBV or HCV infection.
\end{abstract}

Keywords: Hepatocellular carcinoma. Hepatitis B virus. Hepatitis C virus. Alcoholism.

\section{INTRODUCTION}

Hepatocellular carcinoma (HCC) is the seventh most common malignancy worldwide and accounts for nearly 750,000 new cases and 700,000 deaths per year. The incidence of HCC varies greatly around the world, depending on a person's exposure to different risk factors. The incidence is high in Africa and Southeast Asia (13.9 per 100,000 persons in Zimbabwe, 5.1 to 21.0 in China, and 26.9 to 38.1 in Korea) areas in which hepatitis B virus (HBV) is endemic. In contrast, incidence is low in more developed countries such as the United States (from 2.2 to 3.4 in white Americans) and in most European countries ( 0.6 to 2.2 in the United Kingdom and Netherlands, and 1.6 to 10.9 in Austria, Belgium, France, Spain and Germany), with the exception of some countries in Southern Europe (2.8 to 25.0 in Italy) and of Japan (11.4 to 30.4), where

\footnotetext{
Address to: Dr. Fausto Edmundo Lima Pereira. Núcleo de Doenças Infecciosas/ CCS/UFES. Av. Marechal Campos 1468, 29040-091 Vitória, ES, Brasil.

Phone/Fax: 5527 3335-7206

e-mail: felp@ndi.ufes.br

Received 16 June 2014

Accepted 14 October 2014
}

the tumor has a high incidence, with hepatitis $\mathrm{C}$ virus (HCV) being the main associated risk factor ${ }^{1-3}$.

Studies on the incidence of HCC in Brazil are lacking, and the information that does exist originates from four cancer registers in Cuiabá, Goiânia, Brasília (Central west Region) and São Paulo (Southeast Region) ${ }^{3}$. The higher incidence rate was reported in São Paulo: 2.4 and 0.6 cases/100,000, respectively, for men and women ${ }^{3}$. The incidence rates registered in Brazil are similar to those observed in other countries in South and Central America (from 0.6 to 2.1/100,000 in men) ${ }^{3}$.

Approximately 70 to $90 \%$ of patients with $\mathrm{HCC}$ also have chronic liver disease and cirrhosis ${ }^{4,5}$. The main causes of liver cirrhosis in patients with $\mathrm{HCC}$ include infection with hepatitis $\mathrm{B}$ or $\mathrm{C}$ virus, abusive ingestion of alcohol and non-alcoholic steatohepatitis (NASH). Less frequent causes include hereditary hemochromatosis, alpha-1 antitrypsin deficiency, autoimmune hepatitis and porphyrias ${ }^{6,7}$. Hepatitis $\mathrm{B}$ and $\mathrm{C}$ viruses are responsible for approximately $75 \%$ of $\mathrm{HCC}$ cases $^{8}$.

Risk factors associated with this form of cancer were reported in two national surveys, sponsored by the Brazilian Society of Hepatology, that were conducted in $1999^{9}$ and $2010^{10,11}$, as well as in a series of cases from Minas Gerais $(\mathrm{MG})^{12}$. The results of the first survey indicated that HBV was a common factor associated with $\mathrm{HCC}$ in the North and Northeast regions, whereas $\mathrm{HCV}$ was the main risk factor overall, especially in metropolitan areas in the South and Southeast regions?. 
The second survey yielded different results: HCV was found to be the main associated risk factor in all regions, but a high frequency of $\mathrm{HBV}$-associated cases in the North, Central West and Northeast regions was also noted ${ }^{10,11}$. In a series of HCC cases that were diagnosed in Belo Horizonte, MG, the main associated factor was found to be HCV ( $44 \%$ of cases), while HBV infection was observed in $23.5 \%$ of cases $^{12}$. Associated liver cirrhosis has been reported at different frequencies in HCC cases in Brazil, ranging from $87 \%$ in the first national survey ${ }^{9}$ to $98 \%$ in the second survey ${ }^{10,11}$. Because Brazil is a large country and the environmental risk factors for HCC may vary across regions, we chose to examine the main associated risk factors in 274 cases of hepatocellular carcinoma diagnosed at the University Hospital in Vitória; we thus investigated HBV and HCV infections and chronic alcoholism in all cases.

\section{METHODS}

The medical records of 274 consecutive patients who were diagnosed with hepatocellular carcinoma at the University Hospital Cassiano A Morais (HUCAM) between 1993 and 2011 were examined. Age, sex, skin color, and whether cirrhosis or any of the main associated etiological factors presented were recorded for each patient. In addition, medical records were examined for evidence of $\mathrm{HBV}$ and $\mathrm{HCV}$ infection or chronic alcoholism.

In all cases, documentation of alcohol abuse (up to $80 \mathrm{~g}$ per day for over 10 years) and of the presence of hepatitis B surface antigen (HBsAg) was sought, as were anti-HCV antibody levels, as measured by enzyme-linked immunosorbent assay (ELISA) in the clinical laboratory at HUCAM. All anti-HCV-positive cases were confirmed by the detection of viral ribonucleic acid (RNA) in serum.

The diagnosis of hepatocellular carcinoma was confirmed either by histopathology or by imaging (ultrasonography, computerized tomography or magnetic resonance imaging) in conjunction with alpha-fetoprotein measurements. Barcelona's diagnostic criteria ${ }^{13}$ were used when the diagnosis was established using non-invasive methods. The diagnosis of cirrhosis was based on clinical and laboratory data and was confirmed by histology (biopsy or necropsy), imaging methods and endoscopic evidence of esophageal varices. The diagnosis of NASH non-alcoholic steatohepatitis was established when information in the patient's medical record met the diagnostic criteria recently established for this disease ${ }^{14}$. Cases that did not fulfill the criteria for diagnosis of persistent $\mathrm{HBV}$ or $\mathrm{HCV}$ infection, chronic alcoholism or NASH were considered cryptogenic.

\section{Statistical analysis}

Data were analyzed using the Statistical Package for the Social Sciences (SPSS, version 15.0 IBM, Chicago,IL, USA). Comparisons of means, medians and frequencies were performed using either parametric or nonparametric tests, depending on the types and distributions of the variables. A p-value less than 0.05 was considered statistically significant.

\section{Ethical considerations}

The Ethics Committee of Centro de Ciências da Saúde da Universidade Federal do Espírito Santo approved this research.

\section{RESULTS}

Patient age and gender distributions are summarized in Figure 1. The patients were predominantly male $(85.4 \%$ of cases), with a male-to-female ratio of 5.8:1. Most (71.5\%) cases occurred between the fifth and eighth decades of life, with a mean age of $56.6 \pm 14.4$ years and a median age of 57.5 years $(53.4 \pm 13.4$ years, median 57 years in men; $58.1 \pm 19.1$ years, median 62 years in women).

The main risk factors found to be associated with HCC are shown in Table 1. The three most common associated risk factors were the following: persistent $\mathrm{HBV}$ infection, in $37.6 \%$ (23.4\% isolated infections; $14.2 \%$ associated with alcoholism); $\mathrm{HCV}$ infection, in $22.6 \%$ (13.5\% alone; $9.1 \%$ associated with chronic alcoholism); and abuse of alcohol alone, in $17.1 \%$. Non-alcoholic steatohepatitis was found in $2.6 \%$ of cases, and $19.3 \%$ of cases were considered cryptogenic.

The median age and the male-to-female ratio varied with the associated risk factor (Table 1). The male-to-female ratio was higher in cases associated with HBV and abuse of alcohol than in cases with other etiologies or in cases that were cryptogenic.

In $85.4 \%$ of cases, the malignancy was associated with liver cirrhosis. The cases of HCC without associated liver cirrhosis exhibited several differences from cases in which cirrhosis was present. A significantly greater proportion of cases of HCC without cirrhosis were women, compared with cases of HCC with associated cirrhosis (13/40 and 27/234, respectively, $\mathrm{p}<0.001$; male-to-female ratio $2.1: 1$ and 7.6:1, respectively, $\mathrm{p}<0.001)$. Cryptogenic cases were more prevalent among cases without liver cirrhosis than among those with associated liver cirrhosis $(21 / 40$ and $32 / 234$, respectively, $\mathrm{p}<0.001)$. The mean age was $52.6 \pm 19.1$ years in non-cirrhotic cases and $57.4 \pm 13.2$ years in cases associated with cirrhosis $(\mathrm{p}<0.05)$. The age distribution showed a bimodal pattern (Figure 2).

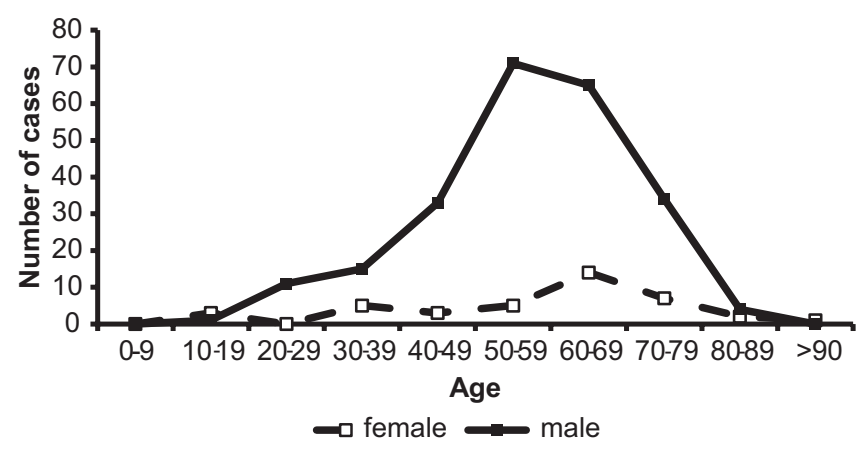

FIGURE 1 - Age and gender distributions of 274 cases of hepatocellular carcinoma diagnosed in Vitória, State of Espírito Santo, Brazil. 
TABLE 1 - Risk factors associated with 274 cases of hepatocellular carcinoma diagnosed in Vitória, State of Espírito Santo, Brazil.

\begin{tabular}{lcccc}
\hline Risk factor* & Number & Percentage & Male-to-female ratio & Age (years; mean \pm SD) \\
\hline HBV & 64 & $23.4^{\mathrm{a}}$ & $60 / 4(15: 1)^{\mathrm{a}}$ & $53.3 \pm 16.0$ \\
HBV plus alcoholism $\#$ & 39 & 14.2 & $39 / 0(39: 0)^{\mathrm{a}}$ & $54.1 \pm 11.4$ \\
HCV & 37 & 15.5 & $26 / 11(2.4: 1)$ & $59.1 \pm 9.8$ \\
HCV plus alcoholism $\#$ & 25 & 9.1 & $25 / 0(25: 0)^{\mathrm{a}}$ & $54.6 \pm 8.5$ \\
Chronic alcoholism & 47 & 17.1 & $46 / 1(46: 1)^{\mathrm{a}}$ & 60.0 \\
Cryptogenic & 53 & 19.3 & $34 / 19(1.7: 1)$ & $62.0 \pm 10.3$ \\
NASH & 7 & 2.6 & $2 / 5(0.4: 1)$ & 61.0 \\
\hline
\end{tabular}

HBV: hepatitis B virus; HCV: hepatitis C virus; NASH: non-alcoholic steatohepatitis. ${ }^{*}$ One case had HBV and HCV infection, and another case had chronic alcoholism and both HBV and HCV infections. ${ }^{a}$ Comparisons of male-to-female ratios: $\mathrm{p}<0.05$ in relation to HCV, cryptogenic and NASH. ${ }^{\#}$ Comparisons of ages: HBV x HBV plus alcoholism, p=0.779; HCV x HCV plus alcoholism, p=0.074.

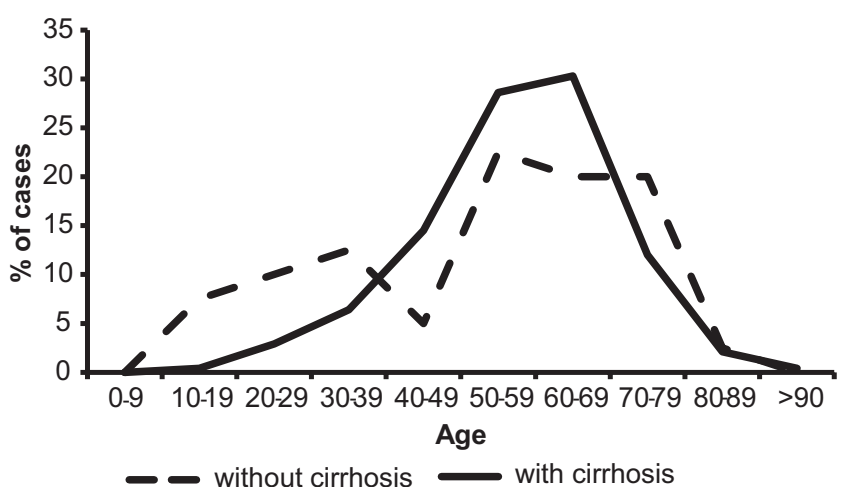

FIGURE 2 - Age distribution of hepatocellular carcinoma with or without associated liver cirrhosis diagnosed in Vitória, State of Espírito Santo, Brazil.

$\mathrm{HBV}$ or HCV infection associated with chronic alcoholism was significantly less frequent in cases without cirrhosis $(\mathrm{p}<0.05)$. However, non-significant differences between the two groups were found for the frequencies of isolated $\mathrm{HCV}$ or $\mathrm{HBV}$ infection, chronic alcoholism alone and NASH (Table 2).

\section{DISCUSSION}

Age at the time of diagnosis and the male-to-female ratio of HCC cases reported here are similar to those reported in the results of two national surveys ${ }^{9,10}$ and in São Paulo ${ }^{11}$ and Minas Gerais $^{12}$. The age at the time of diagnosis is also close to the mean ages reported for areas of intermediate or high incidence of HCC, where this type of cancer is much more commonly observed in men and the mean of age at diagnosis age is between 55 and 59 years (review in reference 6). The ages at the time of diagnosis and the male-to-female ratio observed in cases reported here and in other Brazilian regions suggest that the incidence of HCC in Brazil may be higher than suggested by the low incidence rates reported by the few cancer registries from the Central West and Southeast regions ${ }^{3}$.

The mean age observed in these cases may be related to risk factors, namely, the high prevalence of hepatitis B and chronic alcoholism, alone or associated with $\mathrm{HBV}$ or HCV. In fact, $\mathrm{HCC}$ that is associated with HBV occurs at younger ages, and it is more frequent in men, especially in areas of high prevalence of

TABLE 2 - Risk factors in hepatocellular carcinoma with or without liver cirrhosis, diagnosed in Vitória, State of Espírito Santo, Brazil.

\begin{tabular}{|c|c|c|c|c|}
\hline \multirow[t]{2}{*}{ Risk factor } & \multicolumn{2}{|c|}{ HCC with cirrhosis $(n=234)$} & \multicolumn{2}{|c|}{ HCC without cirrhosis $(n=40)$} \\
\hline & $\mathrm{n}$ & $\%$ & $\mathrm{n}$ & $\%$ \\
\hline $\operatorname{HBV}(n=64)^{*}$ & 54 & 23.0 & 10 & 25.0 \\
\hline $\operatorname{HCV}(n=37)^{*}$ & 34 & 14.5 & 3 & 7.5 \\
\hline Cryptogenic $(n=53)^{\#}$ & 32 & 13.6 & 21 & 52.5 \\
\hline NASH $(n=7)^{*}$ & 6 & 2.5 & 1 & 2.5 \\
\hline
\end{tabular}

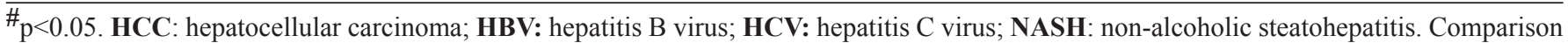
between HCC with cirrhosis and HCC without cirrhosis: *p $>0.05$. 
the virus, where vertical transmission is frequent. In the State of Espírito Santo, where the prevalence of HBV infection is moderate ${ }^{15,16}$, there is indirect evidence of vertical transmission, as more than one case of HBsAg-positive chronic liver disease is frequently observed in the same family at the Gastroenterology Unit of HUCAM (data not shown). On the other hand, when associated with hepatitis virus infection, chronic alcoholism, which is more frequent in men, accelerates the progression of liver lesions related to viral infection, especially those associated with $\mathrm{HCV}^{5,17,18}$. This accelerated progression, manifested by a younger age at the time of diagnosis was not observed in the cases reported here. Although lower median ages were observed in HCV and HBV cases associated with chronic alcoholism, the differences did not reach statistical significance.

While the results presented in this paper confirmed the large variation in the etiological factors of HCC that is observed worldwide, these findings nonetheless differ in several respects from those reported for most countries and for other regions of Brazil. In a recent review by El Seragh et $\mathrm{al}^{19}, \mathrm{HCV}$ was noted to be the most common risk factor in Japan, Italy and the United States, whereas in sub-Saharan Africa and Southeast Asia, the main risk factor is HBV.

$\mathrm{HCV}$ infection was present in $22.6 \%$ of $\mathrm{HCC}$ cases, which is lower than the $54 \%, 44 \%$ and $38 \%$ of cases reported in recent surveys in Brazil ${ }^{11}$ and case series from Minas Gerais ${ }^{12}$ and Latin America ${ }^{20}$, respectively. This variability reflects differences in exposure to risk factors for chronic liver disease in our county, where alcoholism and chronic infection with hepatitis B virus are more prevalent than in other regions of Brazil or Latin America $^{21}$. The high frequency of HBV associated with HCC reported here (37.6\% of the cases) is noteworthy. This prevalence is higher than the $16 \%$ reported in a recent nationwide survey of Brazil ${ }^{10,11}$ and the $23.5 \%$ in Minas Gerais ${ }^{12}$. This difference is in agreement with the moderate prevalence of hepatitis B virus infection in the State of Espírito Santo, where there are areas in which the prevalence of HBsAg ranges from 1.2 to $6.7 \%{ }^{15,16}$. Moreover, these results are consistent with previous reports of a high frequency of HBsAg-positive hepatocellular carcinomas diagnosed at the University Hospital in Vitória during a period of time before the cases reported here were diagnosed ${ }^{22}$.

Another important feature of the data presented here is the high frequency with which chronic alcoholism was observed in HCC cases; chronic alcoholism was present in $40.4 \%$ of cases $(17.1 \%$ as the only associated factor; $23.3 \%$ associated with $\mathrm{HBV}$ or HCV infection). These data reflect the high prevalence of alcohol abuse in metropolitan Vitória (27.8\% in men; $10.8 \%$ in women ${ }^{23}$ and the high frequency of chronic alcoholism in the etiology of liver cirrhosis in the State of Espírito Santo ${ }^{21}$. In addition, this observation confirms the importance of the abusive use of alcohol in the development of $\mathrm{HCC}^{6,17,18,24}$. A recent study reported changes in the etiology of HCC in Italy, with an increasing number of cases associated with abusive alcohol ingestion in the last ten years ${ }^{25}$.

Non-alcoholic steatohepatitis was identified in $2.6 \%$ of cases, a prevalence similar to that reported in the last national survey ${ }^{10,11}$. An increased number of NASH-associated HCC has also been observed in more developed countries ${ }^{26}$, and it is possible that some cryptogenic cases may be related to unidentified NASH, instead, as has been hypothesized previously ${ }^{5,27,28}$. Cryptogenic cases accounted for $19.3 \%$ of our sample, which is a greater frequency than that reported for the most recent national survey in Brazil. The high frequency of cryptogenic cases may result from the under-diagnosis of NASH but may also be due to other environmental, etiological factors such as food contamination by aflatoxins, which has been reported in Brazil ${ }^{29}$. However, we do not know what the impact of these mycotoxins may be on the etiology of HCC in Brazil. A mutation at codon 249 of TP53 occurred in $14.6 \%$ of 41 cases of $\mathrm{HCC}$ diagnosed in Vitória ${ }^{30}$, an indirect indication of moderate exposure to aflatoxin in our county. It is also possible that occult HBV infection may have been present in some HBsAg-negative cases ${ }^{31-33}$ and that it could thus help to explain the greater frequency of cryptogenic cases; however, this possibility was not investigated for the cases reported here.

The proportion of cases associated with liver cirrhosis was $85.4 \%$, which is consistent with that reported in the literature (cirrhosis has been found to occur in 80 to $90 \%$ of cases of $\mathrm{HCC}^{5,19}$ ). However, the frequency of cirrhosis was lower than that reported for the second national survey ${ }^{10,11}$, in which cirrhosis was associated with $98 \%$ of cases. In case series of HCC from Minas Gerais ${ }^{12}$, no information on the frequency of associated liver cirrhosis is reported. We do not have a definitive explanation for this difference and hypothesize that it may be related to the quality of the samples studied; in health units that are specialized in the care of cirrhotic patients, the frequency of HCC with associated cirrhosis may be greater than that in a general hospital with a gastroenterology unit that admits patients with all types of liver disease.

Reported cases of HCC in the non-cirrhotic liver have exhibited peculiar characteristics with respect to age group, gender and etiology, although the reported findings have been inconsistent ${ }^{5,34,35}$. For the 40 cases of hepatocellular carcinoma without liver cirrhosis in our sample, the male-to-female ratio was lower than for cases that were associated with liver cirrhosis. Moreover, the age distribution was different from that observed for cases associated with cirrhosis, with a lower mean age, a bimodal distribution, and a higher proportion of cases diagnosed before the fifth decade. Cryptogenic cases were more frequent among non-cirrhotic $\mathrm{HCC}$ cases. The occurrence of three cases of HCV-positive HCC in non-cirrhotic patients confirms that, infrequently, $\mathrm{HCV}$ may induce this type of cancer without any accompanying liver cirrhosis, as has been reported by other authors ${ }^{36-38}$.

In conclusion, the results reported here demonstrate that the main risk factor associated with HCC in the State of Espírito Santo was infection with HBV. Additionally, this risk factor was observed more frequently in patients in this study than in patients studied in São Paulo and Minas Gerais, confirming the substantial geographic variation in risk factors associated with this malignancy in Brazil. Furthermore, our results demonstrate that chronic alcoholism was an important risk factor, alone or in association with HBV or HCV infection. 


\section{CONFLICT OF INTEREST}

The authors declare that there is no conflict of interest.

\section{REFERENCES}

1. Ferlay J, Shin HR, Bray F, Forman D, Mathers C, Parkin DM. Estimates of worldwide burden of cancer in 2008: GLOBOCAN 2008. Int J Cancer 2010; 127:2893-2917.

2. Venook AP, Papandreou C, Furuse J, Guerra LL. The incidence and epidemiology of hepatocellular carcinoma: a global and regional perspective. Oncologist 2010; 15 (supl 4):5-13.

3. Curado MP, Edwards B, Shin HR, Storm H, Ferlay J, Heanue M, et al. Cancer Incidence in Five Continents, Vol. IX. IARC Scientific Publication n. 160; 2012. p. 696-700.

4. Forner A, Llovet JM, Bruix J. Hepatocellular carcinoma. Lancet 2012; 379:1245-1255.

5. Fattovich G, Stroffolini T, Zagni I, Donato F. Hepatocellular carcinoma in cirrhosis: incidence and risk factors. Gastroenterol 2004; 127:S35-S50.

6. El-Serag HB, Rudolph KL. Hepatocellular carcinoma: epidemiology and molecular carcinogenesis. Gastroenterology 2007; 132:2557-2576.

7. Blonski W, Kotlyar DS, Forde KA. Non-viral causes of hepatocellular carcinoma.World J Gastroenterol 2010; 16:3603-3615.

8. Yang JD, Roberts LR. Epidemiology and management of hepatocellular carcinoma. Infect Dis Clin North Am 2010; 24:899-919.

9. Gonçalves CS, Pereira FE, Gayotto LC. Hepatocellular carcinoma in Brazil: report of a national survey (Florianópolis, SC, 1995). Rev Inst Med Trop Sao Paulo 1997; 39:165-170.

10. Carrilho FJ, Kikuchi L, Branco F, Gonçalves CS, Mattos AA, Brazilian HCC Study Group. Clinical and epidemiological aspects of hepatocellular carcinoma in Brazil. Clinics (São Paulo) 2010; 65:1285-1290.

11. Kikuchi L, Chagas AL, Alencar RS, Paranaguá-Vezozzo DC, Carrilho FJ. Clinical and epidemiological aspects of hepatocellular carcinoma in Brazil. Antivir Ther 2013; 18:445-449.

12. Osório FM, Lauar GM, Lima AS, Vidigal PV, Ferrari TC, Couto CA. Epidemiological aspects of hepatocellular carcinoma in a referral center of Minas Gerais, Brazil. Arq Gastroenterol 2013; 50:97-100.

13. Bruix J, Sherman M, Llovet JM, Beaugrand M, Lencioni R, Burroughs AK, et al. EASL Panel of Experts on HCC. Clinical management of hepatocellular carcinoma. Conclusions of the Barcelona-2000 EASL conference. European Association for the Study of the Liver. J Hepatol 2001; 35:421-430.

14. Chalasani N, Younossi Z, Lavine JE, Diehl AM, Brunt EM, Cusi K, et al. The Diagnosis and Management of Non-Alcoholic Fatty Liver Disease: Practice Guideline by the American Association for the Study of Liver Diseases, American College of Gastroenterology, and the American Gastroenterological Association. Hepatol 2012; 55:2005-2023.

15. Yoshida CF, Camargo IF, Mercadante LA, Gaspar AM, Gomes DF, Schatzmayr HG. Hepatitis B serological patterns of asymptomatic carriers in an endemic region and evaluation of blood plasma as a source of hepatitis B vaccine. Vaccine 1986; 4:253-256.

16. Pereira AM, Andrade RLM. Inquérito epidemiológico de soroprevalência do vírus B da hepatite no Estado do Espírito Santo, 19951996. Boletim Epidemiológico, Secretaria de Estado da Saúde do Espírito Santo 2001; 1:19-23.

17. Donato F, Tagger A, Gelatti U, Parrinello G, Boffetta P, Albertini A, et al. Alcohol and hepatocellular carcinoma: the effect of lifetime intake and hepatitis virus infections in men and women. Am J Epidemiol 2002; 155:323-331.

18. Morgan TR, Mandayam S, Jamal MM. Alcohol and hepatocellular carcinoma. Gastroenterol 2004; 127 (supl 1):87-96.
19. El-Serag HB. Epidemiology of viral hepatitis and hepatocellular carcinoma. Gastroenterol 2012; 142:1264-1273.

20. Fassio E, Díaz S, Santa C, Reig ME, Martínez-Artola Y, Alves-deMattos A, et al. Multicenter Group for Study of Hepatocarcinoma in Latin America. Asociación Latinoamericana para el Estudio del Hígado (ALEH). Etiology of hepatocellular carcinoma in Latin America: a prospective, multicenter, international study. Ann Hepatol 2010; 9:63-69.

21. Gonçalves PL, Zago-Gomes MP, Marques CC, Mendonça AT, Gonçalves CS, Pereira FE. Etiology of liver cirrhosis in Brazil: chronic alcoholism and hepatitis viruses in liver cirrhosis diagnosed in the state of Espírito Santo. Clinics (Sao Paulo) 2013; 68:291-295.

22. Pereira FEL, Gonçalves CS, Boni ES. The association of hepatitis B surface antigen (HBsAg) with hepatocelular carcinoma in Espiríto Santo State, Brazil. Brazilian J Med Biol Res 1981; 14:277-280.

23. Ministério da Saúde.Indicadores de fatores de risco e de proteção. Brasília: Ministério da Saúde; Available at: http://tabnet.datasus.gov.br. [Cited 2012, nov 2014].

24. Lin CW, Lin CC, Mo LR, Chang CY, Perng DS, Hsu CC, et al. Heavy alcohol consumption increases the incidence of hepatocellular carcinoma in hepatitis B virus-related cirrhosis. J Hepatol 2013; 58:730-735

25. Santi V, Buccione D, Di Micoli A, Fatti G, Frigerio M, Farinati F, et al. The changing scenario of hepatocellular carcinoma over the last two decades in Italy. J Hepatol 2012; 56:397-405.

26. Takuma Y, Nouso K. Nonalcoholic steatohepatitis-associated hepatocellular carcinoma: our case series and literature review. World $\mathrm{J}$ Gastroenterol 2010; 16:1436-1441.

27. Liou I, Kowdley KV. Natural history of nonalcoholic steatohepatitis. J Clin Gastroenterol 2006; 40 (supl 1):11-16.

28. Baffy G, Brunt E, Caldwell. Hepatocellular carcinoma in non-alcoholic fatty liver disease: an emerging menace. J Hepatol 2012; 56:1384-1391.

29. Andrade PD, Mello MH, França JA, Caldas ED. Aflatoxins in food products consumed in Brazil: a preliminary dietary risk assessment. Food Addit Contam Part A Chem Anal Control Expo Risk Assess 2013; 30:127-136.

30. Carvalho FM, Almeida Pereira T, Gonçalves PL, Jarske RD, Pereira FE, Louro ID. Hepatocellular carcinoma and liver cirrhosis TP53 mutation analysis reflects a moderate dietary exposure to aflatoxins in Espírito Santo State, Brazil. Mol Biol Rep 2013; 40:4883-4887.

31. Raimondo G, Allain JP, Brunetto MR, Buendia MA, Chen DS, Colombo M, et al. Statements from the Taormina expert meeting on occult hepatitis B virus infection. J Hepatol 2008; 49:652-657.

32. Ikeda K, Kobayashi M, Someya T, Saitoh S, Hosaka T, Akuta N, et al. Occult hepatitis B virus infection increases hepatocellular carcinogenesis by eight times in patients with non-B, non-C liver cirrhosis: a cohort study. J Viral Hepat 2009; 16:437-443.

33. Shi Y, Wu YH, Wu W, Zhang WJ, Yang J, Chen Z. Association between occult hepatitis B infection and the risk of hepatocellular carcinoma: a meta-analysis. Liver Int 2012; 32:231-240.

34. Kumar M, Kumar R, Hissar SS, Saraswat MK, Sharma BC, Sakhuja P, et al. Risk factors analysis for hepatocellular carcinoma in patients with and without cirrhosis: a case-control study of 213 hepatocellular carcinoma patients from India. J Gastroenterol Hepatol 2007; 22:1104-1111.

35. Trevisani F, Frigerio M, Santi V, Grignaschi A, Bernardi M. Hepatocellular carcinoma in non-cirrhotic liver: a reappraisal. Dig Liver Dis 2010; 42:341-347.

36. Nash KL, Woodall T, Brown AS, Davies SE, Alexander GJ. Hepatocellular carcinoma in patients with chronic hepatitis $\mathrm{C}$ virus infection without cirrhosis. World J Gastroenterol 2010; 16:4061-4065.

37. Yeh MM, Daniel HD, Torbenson M. Hepatitis C-associated hepatocellular carcinomas in non-cirrhotic livers. Mod Pathol 2010; 23:276-283.

38. Albeldawi M, Soliman M, Lopez R, Zein NN. Hepatitis C VirusAssociated Primary Hepatocellular Carcinoma in Non-cirrhotic Patients. Dig Dis Sci 2012; 57:3265-3270. 